\title{
Obstetric ultrasound - its risks and the cost of addressing them
}

\author{
G R Howarth, ${ }^{1}$ MB ChB, MMed (O\&G), MPhil (Bioethics); S Bown, ${ }^{2}$ LLB (Hons), MRCP, DRCOG, FFFLM \\ ${ }^{1}$ Medicolegal Advisor and Head of Medical Services - Africa, Medical Protection Society, London, United Kingdom \\ ${ }^{2}$ Director of Policy and Communications, Medical Protection Society, London, United Kingdom
}

Corresponding author: G R Howarth (graham.howarth@mps.org.uk)

Until recently, obstetric claims (which are invariably high-value) used to be clustered around problems related to labour. However, a second group of high-value claims is emerging: those related to missed abnormaltities. The value of claims is now so high that a single individual is unable to compensate a claimant adequately, and indemnity is therefore essential. Although such claims are relatively rare, indemnity costs are high as the claims are large. The high value of obstetric claims, including those for missed abnormalities, is reflected in the cost of indemnity for obstetricians and those performing antenatal ultrasound.

S Afr J Rad 2013;17(3):98-99. DOI:10.7196/SAJR.927

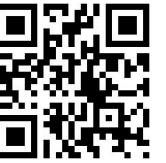

Children born following obstetric misadventure are usually severely compromised and require specialised care and sophisticated treatment that allows them to live longer and more fulfilling lives. Owing to costly care and longer life expectancy, raising such children is expensive; therefore, understandably, the cost of obstetric claims is high, and settlements can easily reach eight-figure sums. Accordingly, indemnity costs for obstetricians are far higher than most other specialties; with few exceptions, obstetricians' indemnity costs are multiples of those of other specialities, and may threaten private obstetric care in South Africa by the end of the decade. ${ }^{[1,2]}$

Until fairly recently, most high-value obstetric claims concerned intrapartum problems - mainly cerebral palsy related to mismanaged intrapartum care. However, a second group of high-value claims is now emerging: those related to missed abnormalities. ${ }^{[3]}$ The gist of the allegations in these claims is that structural abnormalities were missed during an antenatal ultrasound examination. Had the parents been aware of the severity of the abnormality that was missed, they claim that they would have elected to terminate the pregnancy. Alternatively, if the parents felt that they would have decided against terminating the pregnancy, they allege that intra-uterine diagnosis and alternative management of the pregnancy or delivery would have alleviated complications and some of the costs for caring for the child. The latter is a classic claim in medical negligence not dissimilar to any claim for the financial consequences of a delayed or missed diagnosis. The former is a claim by the parents for wrongful birth, holding the defendant responsible for the extra costs of raising the compromised child. ${ }^{[4]}$ South African law does not allow a child to sue for wrongful life. , 5,6$]^{-6}$

With modern ultrasound equipment, it is possible for the trained observer to diagnose the majority of major structural abnormalities antenataly. ${ }^{[7]}$ The converse is also true; if abnormalities can be seen, they can also be missed. As most major abnormalities can and will be seen on ultrasound, it follows that when missed, successful defence of a case may be difficult as the claimant will argue that 'on the balance of probabilities', the abnormality should have been seen. Defending a case may also be made more difficult by reviewing images of an ultrasound, given to the patient as a keepsake, that clearly demonstrate the abnormality.

To date, all that was needed to perform ultrasound in pregnancy was appropriate equipment, an operator and a willing pregnant patient. ${ }^{[8]}$ Each time an obstetric ultrasound is performed, there is a risk that an abnormality may be missed. While the chance of missing an abnormality in a particular scan is low, the risk among a cohort of scans is not; abnormalities, including major structural abnormalities, are missed, even by experts. The issue is compounded by the magnitude of a claim for a missed abnormality. Unfortunately, such claims tend to be high, and can also easily run into millions of Rand. While an individual's risk of having a claim made may be relatively low, the magnitude of a missed abnormality claim's value is so high that a single individual could not afford to compensate a deserving claimant. ${ }^{[1,9]}$ What can individuals do to negate that risk? They can avoid the risk by no longer performing obstetric ultrasound or they can try to decrease the risk of missing a structural abnormality by increasing their knowledge and expertise. While the former action is a solution, the second merely decreases but does not remove the risk; even experts miss structural abnormalities. While improving operator knowledge and skill may be helpful, the only way of performing obstetric ultrasound and avoiding the financial risk of a missed abnormality is by transferring that risk to either an insurer or a not-for-profit indemnifier. Now one has to add appropriate indemnity to the requirements for performing obstetric ultrasound!

While large insurers or indemnifiers will have the capacity to meet high claims costs, they, like the individuals confronted by the risk, need to decide whether or not they will accept the risk. If they wish to avoid the risk of claims for missed structural abnormalities, they can either decline to accept the risk or make their product unaffordable - risk avoidance. If they decide to accept the risk, they may wish to decrease it, one approach being to insist that those performing these specialised scans have predetermined training, knowledge or expertise. 
Most importantly, indemnifiers accepting the financial risks of claims for missed structural abnormalities need to ensure they have sufficient reserves to meet future administrative and claims costs. To do this, they perform actuarial risk assessments to determine the reserves needed to meet the financial risk of missed structural abnormalities, given the chance of an abnormality being missed and the magnitude of claims anticipated. Once the magnitude of the financial risk for missed structural abnormalities has been calculated, it has to be decided who should pay for the risk. There can only be one equitable answer: If you contribute to the financial risk, you must contribute to covering it. Only one question remains: How much should individuals contribute? Again, there is only one equitable answer: Each individual who contributes to the risk has to contribute to the covering of the risk. The person who performs the ultrasound is the individual who may be sued for missing an abnormality, and it is important that that individual is appropriately indemnified. If the individual is an employee, it is important that the employer either requires that their employees make their own arrangements for appropriate indemnity, or the employer pays for the indemnity arrangements for the employee.

Although the chances of missing a major structural abnormality on a single scan are low, claims are likely to be very high, and indemnifying the risk will be correspondingly expensive. Making those who take the financial risk of missing a structural abnormality pay to cover their own risk will have consequences. Given that the fee for an individual antenatal scan is low, some will be unable to absorb the cost by performing a few extra scans. Many may feel that they cannot afford the cost increase and, unable to bear the financial risk themselves, may have to give up obstetric ultrasound.

Rather than precluding the performing of ultrasound in pregnancy, is there an alternative? Are there scans that can be performed that are lower-risk and require less expertise, for which indemnity therefore costs less? There are; first trimester scans confirming pregnancy, its location and gestational age are of lower risk and can be performed by those with less expertise who are exposed to less financial risk. It is important to note the distinction between these restricted first trimester scans and the higher risk first trimester scans evaluating intracranial and/or nuchal translucency; clearly these scans also require specialist expertise. Those performing the simpler scans need to ensure that patients understand the limits of the restricted scan, and that the pregnancy is not being screened for genetic or structural abnormalities. To reinforce the message, patients need to be informed of the prudence of having a fetal evaluation scan performed by someone else who has the appropriate expertise and indemnity. The conversation with the patient needs to be contemporaneously documented and the documentation retained. Neither the nuchal nor the intracranial translucency should be evaluated or measured, and no image should be given to the patient that shows either.

Some professionals who are trained and competent to perform obstetric scans later in pregnancy may be discouraged by high indemnity costs but are concerned about where this leaves their professional obligations in certain circumstances. 'What if' arguments arise, a classic one being: What if you decline to perform a second or third trimester scan, despite having the equipment and a degree of expertise, because you do not have the appropriate indemnity? Are you not vulnerable to criticism from the Health Professions Council of South Africa (HPCSA) for failing to act in the patient's best interests? To be vulnerable to criticism from the HPCSA, the individual would have to unreasonably decline to perform a scan in a true emergency situation with nobody else appropriate available. It is important to remember that few obstetric ultrasound scans are true emergencies; additionally, in the vast majority of private patients, an earlier scan will be available that is of assistance. While an urgent scan may be reassuring or helpful, it may not be clinically essential.

A few true emergencies do spring to mind, however; e.g. placental localisation in a pregnant patient who is bleeding painlessly near term and does not have a previous ultrasound; or evaluation of fetal heart activity in a patient with a viable fetus and a clinical diagnosis of probable placental abruption. Confirmation of fetal heart activity may allow for a life-saving caesarean section, while the absence of fetal heart activity would save the mother an unnecessary and dangerous caesarean section. Were an abnormality missed in these life-threatening emergency situations where action and time are of the essence, it is unlikely that, under the circumstances, an individual would be found negligent of missing a structural abnormality. Additionally, it is unlikely that there would be any liability as delivery would be imminent, and it is unlikely that there would be time or opportunity to modify the outcome. In such cases, the litigation risks are very low and could be carried by the individual probably at little financial risk to themselves. If sued, however, and the individual was indemnified by a discretionary organisation, the individual could always approach the organisation to exercise their discretion positively.

A claim following a missed structural or chromosomal abnormality is rare but expensive to settle, leading to increased indemnity costs. Those wishing to perform obstetric ultrasound need to ensure that they are appropriately and adequately indemnified, giving them and their patients peace of mind.

1. Howarth GR. The threat of litigation: Private obstetric care - quo vadis? South African Journal of Bioethics and Law 2011;4(2):85-88.

2. Howarth GR. Obstetric risk avoidance: Will anyone be performing private obstetrics by the end of the decade? S Afr Med J 2013;103(8):513-514. [http://dx.doi.org/10.7196/SAMJ.7233]

3. NHS Litigation Authority. Ten years of maternity claims. An analysis of NHS Litigation Authority Data. London: NHS Litigation Authority, 2012.

4. Friedman v Glicksman 19961 SA 1134 (W).

5. Stewart v Botha (340/2007) [2008] ZASCA 84 (3 June 2008).

6. Sithole S. Liability of medical practitioners to children born with congenital defects - a discussion of Stewart v. Botha. South African Journal of Bioethics and Law 2009;2(2):41-42.

7. Chaoui R, Nicolaides KH. From nuchal translucency to intracranial translucency: Toward the early detection of spina bifida. Ultrasound Obstet Gynecol 2010;35:133-138. [http://dx.doi.org/10.1002/ uog.7552]

8. Geerts L. Ultrasound services in our rainbow nation - many shades of grey? South African Journal of Obstetrics and Gynaecology 2010;18(2):34-35.

9. Howarth GR, Bown $S$, Whitehouse $S$. The importance of comprehensive protection in today's healthcare environment. S Afr Med J 2013;103(7):453-454. [http://dx.doi.org/10.7196/SAMJ.7106] 